\title{
Systemic Inflammation in Chronic Obstructive Pulmonary Disease: May Adipose Tissue Play a Role? Review of the Literature and Future Perspectives
}

\author{
Ruzena Tkacova \\ Department of Respiratory Medicine and Tuberculosis, Faculty of Medicine, P. J. Safarik University, L. Pasteur Teaching Hospital, \\ Kosice 041 90, Slovakia \\ Correspondence should be addressed to Ruzena Tkacova, ruzena.tkacova@upjs.sk
}

Received 6 November 2009; Revised 9 January 2010; Accepted 9 February 2010

Academic Editor: Giamila Fantuzzi

Copyright ( $) 2010$ Ruzena Tkacova. This is an open access article distributed under the Creative Commons Attribution License, which permits unrestricted use, distribution, and reproduction in any medium, provided the original work is properly cited.

Chronic obstructive pulmonary disease (COPD) is a major cause of morbidity and mortality worldwide. Low-grade systemic inflammation is considered a hallmark of COPD that potentially links COPD to increased rate of systemic manifestations of the disease. Obesity with/without the metabolic syndrome and cachexia represent two poles of metabolic abnormalities that may relate to systemic inflammation. On one hand systemic inflammatory syndrome likely reflects inflammation in the lungs, i.e. results from lung-to plasma spillover of inflammatory mediators. On the other hand, obesity-related hypoxia results in local inflammatory response within adipose tissue per se, and may contribute to elevations in circulatory mediators by spillover from the adipose tissue to the systemic compartment. The extent to which systemic hypoxia contributes to the adipose tissue inflammation remains unknown. We assume that in patients with COPD and concurrent obesity at least three factors play a role in the systemic inflammatory syndrome: the severity of pulmonary impairment, the degree of obesity-related adipose tissue hypoxia, and the severity of systemic hypoxia due to reduced pulmonary functions. The present review summarizes the epidemiological and clinical evidence linking COPD to obesity, the role of adipose tissue as an endocrine organ, and the role of hypoxia in adipose tissue inflammation.

\section{Introduction}

According to the WHO, chronic obstructive pulmonary disease (COPD) is one of the most prevalent diseases, expected to move to the 3rd leading cause of mortality in 2020 [1]. COPD is characterized by poorly reversible airflow limitation that is usually progressive and associated with an abnormal inflammatory response of the lungs to noxious particles or gases, particularly cigarette smoke [2]. Nevertheless, the pathological mechanisms and clinical manifestations of COPD are not restricted only to pulmonary inflammation and airway remodeling [3]. In contrast, over the last decade, the recognition of COPD as a systemic disease has developed. The best recognized systemic manifestations of COPD include systemic inflammation, cardiovascular comorbidities, cachexia and muscle dysfunction, osteoporosis, anemia, and clinical depression and anxiety [4,
5]. Chronic comorbidities affect health outcomes in patients with COPD, including mortality. In fact, the majority of patients with COPD die of nonrespiratory disorders such as cardiovascular diseases or cancer [6].

Low-grade systemic inflammation can be defined as a two- to fourfold elevation in circulating levels of proinflammatory and anti-inflammatory cytokines, naturally occurring cytokine antagonists, acute phase proteins, as well as minor increases in counts of neutrophil and natural killer cells [7]. Systemic inflammation is considered a hallmark of COPD and one of the key mechanisms that may be responsible for the increased rate of comorbidities, including cardiovascular complications in COPD [8]. Obesity with/without the metabolic syndrome on one hand and cachexia on the other represent two poles of metabolic abnormalities that may relate to systemic inflammation. Respirologists are routinely challenged by the presentation 
of obesity concurrently with COPD, particularly in GOLD stages 1 and 2 [9]. Obesity and cachexia are clinically significant and challenging in both clinical practice and translational research of systemic manifestations of COPD $[9,10]$.

Increased expression and secretion of proinflammatory adipokines resulting from obesity and/or hypoxia in patients with COPD may represent a contributing mechanism aggravating the overall systemic inflammatory pattern in this multicomponent disease. Although the extent to which adipose tissue production and release of inflammatory cytokines contributes to the chronic systemic inflammatory syndrome in COPD is not yet well defined, several stimulating ideas can be derived from experimental studies aimed to unravel the effects of hypoxia in adipocyte cell cultures, from animal hypoxic models, and from disorders other than COPD. The purpose of this review is to summarize recent advances and to outline future perspectives in the search for the evidence of the potential role of adipose tissue in the systemic inflammation in patients with COPD.

\section{Search Strategy}

A search of scientific literature was performed to identify relevant studies on the topic. Following electronic databases were searched: Cochrane Database of Systematic Reviews, Medline via PubMed, and Google Scholar. Specific keywords, terms, and their combinations including searches with MESH terminology (i.e., "obesity and COPD and review") were used in three areas: (1) terms related to clinical manifestations of COPD: "chronic obstructive pulmonary disease", "adipose tissue", "morbidity", "mortality", "clinical outcomes", "exacerbation", "comorbidities", "systemic manifestations", "obesity", "cachexia", "weight loss"; (2) terms related to systemic inflammation: "systemic inflammation", "hypoxia", "inflammatory cytokines", "adipokines", "transcription factors", "gene expression", "tumor necrosis factor", "interleukin", "hypoxia-inducible factor", "nuclear factor-kappa B"; (3) terms related to metabolic state: "insulin resistance", "nutrition", "body composition", "fat mass", "fat-free mass", "resting energy expenditure". The searches were limited to papers published in English-language journals in the last 15 years. In addition, we searched relevant guidelines and latest editions of internal and respiratory medicine textbooks. Given the journal space limits, we restrict the present review to the most robust, relevant, and important studies in the reviewed topic.

\section{Systemic Inflammation in COPD}

3.1. COPD—Chronic Systemic Inflammatory Syndrome. Recently, Fabbri and Rabe [11] proposed an overreaching approach to diagnosis, assessment of severity, and management of COPD and its frequent comorbidities that aims not to restrict the diagnostic approach to COPD alone but to search for the signs of the more general disorder termed "chronic systemic inflammatory syndrome". The rationale for this proposal described in details in Lancet [11] can be shortly summarized as (a) systemic inflammation as the most likely key common mechanism by which major risk factors such as smoking, hyperlipidemia, obesity, and hypertension lead to chronic diseases [12] including COPD, (b) the presence of at least three chronic medical conditions in almost half of all people aged 65 years or older, with comorbid conditions accounting for more than 50\% of health-care resources in patients with COPD [13].

The epidemiological, pathogenetic, and clinical evidence linking COPD to chronic systemic inflammatory syndrome is rapidly growing. Even during stable COPD, increases in a number of inflammatory proteins were described in the systemic circulation including C-reactive protein (CRP) [7, 14-16], tumor necrosis factor-alpha (TNF- $\alpha$ ), interleukin (IL)-6 [17] and IL-8 [18]. Small but significant increases in circulating levels of both the soluble TNF receptors 55 and 75 (sTNF-R55 and sTNF-R75) [18], IL-10 [19] and IL-18 [20] have also been reported in such patients. Importantly, epidemiological studies suggest relationships between circulatory inflammatory mediators and reductions in pulmonary functions reflected by decreases in forced expiratory volume in one second $\left(\mathrm{FEV}_{1}\right)$. Such relationships were observed between pulmonary functions and circulatory CRP $[7,21]$ or IL-6 [22]. Moreover, some evidence suggests that the systemic proinflammatory state is likely not counterbalanced by up-regulation of anti-inflammatory proteins. Indeed, Dentener et al. [14] documented that levels of the anti-inflammatory mediator-soluble interleukin 1 receptor II (sIL-1RII) were similar in patients with stable COPD compared to healthy subjects, despite markedly increased sTNF-R55. It is important to underline that significant repeatability of circulatory inflammatory biomarkers such as IL-6, TNF- $\alpha$, and CRP over twelve-month period, with a robust and repeatable association between IL- 6 and CRP levels was recently demonstrated [23].

COPD exacerbations are associated with further increases in markers of both bronchial and systemic inflammation over and above levels present during the stable phase of the disease [24-26]. In addition, the rate of decline of inflammatory mediators such as CRP during exacerbations of COPD is significantly diminished compared to other inflammatory conditions such as pneumonia, with only $6 \%$ of COPD patients responding by CRP reductions on the second day of hospitalization following antibiotic administration [27].

3.2. Origin of Systemic Inflammation in COPD. Might COPD-associated chronic inflammatory syndrome reflected by increases in circulatory concentrations of inflammatory proteins relate to concurrent obesity or cachexia? In COPD, two main sources of inflammatory mediators may be considered: lungs and peripheral organs including adipose tissue. Indeed, there is a long-lasting debate whether, in patients with COPD, the local inflammation in the pulmonary compartment spills over into the circulation or rather there is an enhanced production of inflammatory mediators in nonpulmonary compartment as well. Approaching this question is rather challenging since plasma biomarkers such as CRP, TNF- $\alpha$, interleukins, and fibrinogen are clinically relevant $[28,29]$ but are synthesized predominantly in the liver 
and, thus, their relationship with COPD and lung functions remains uncertain $[30,31]$. Analysis of the origin of systemic inflammation in COPD might require different approach: to study either lung-specific proteins (i.e., pneumo-proteins) whoes plasma concentrations are largely determined by the rate of synthesis and translocation across the lung-blood barrier, and/or adipose-tissue specific proteins in association with measurements of arteriovenous differences in the concentrations of the respective inflammatory mediators (Sin DD, personal communication).

\subsubsection{Lung-to-Blood Translocation of Inflammatory Media-} tors. Recently, the concept of systemic inflammation as a consequence of spillover of inflammatory mediators from the lungs to the systemic compartment in COPD has been broadly discussed [32-34]. Several lines of evidence suggests that smoking per se and/or COPD increase permeability of pulmonary vessels, and therefore contribute to the spillover of inflammatory mediators from the pulmonary to the systemic compartment [35-38]. First, in airway cell line in vitro, exposure to cigarette smoke transiently decreases transepithelial resistance in association with increases in macromolecular permeability [37]. Second, experimental studies in mice suggest that lung injury induced by bleomycin exposure leads to increased leak of surfactant protein D (SP-D), a lung specific protein from the pulmonary to the systemic compartment [39]. Also, lung-to-blood translocation of IL-6, a primary inflammatory cytokine, has been documented following exposure to endotoxin [40]. Third line of evidence on the lung-to-blood translocation of inflammatory mediators comes from human studies. Kennedy et al. [35] identified higher alveolar-capillary membrane permeability in smokers compared to nonsmokers using the most direct measurement of the blood-gas barrier permeability by radioactive-labeled hydrophilic solute ${ }^{99 \mathrm{~m}}$ Tc-labelled diethylenetriaminepentaacetic acid (DTPA) following its inhalation and clearance from the alveoli into the pulmonary capillary blood. Moreover, Wollmer and Evander [36] demonstrated that lung clearance of DTPA is inversely related to $\mathrm{FEV}_{1}$ such that subjects with the lowest pulmonary function had the highest values of permeability. Conversely, improvements in $\mathrm{FEV}_{1}$ following therapy with inhaled steroids were accompanied by significant reductions in alveolar-capillary membrane permeability in symptomatic patients with COPD [41]. Also, reductions in serum levels of several inflammatory mediators including lung-specific proteins such as surfactant protein-D were observed in patients with moderate-tosevere COPD following therapy with inhaled corticosteroids [42, 43].

3.2.2. Increases in Inflammatory Cytokine Production and Release from Peripheral Tissues. In conditions other than COPD, large number of studies suggest that both liver and adipose tissue express a wide variety of proinflammatory mediators that are released to the systemic circulation, and have potential systemic effects. In the pathogenesis of lowgrade subclinical inflammation in obesity, the importance of adipokines released from adipose tissue is increasingly recognized. Indeed, visceral fat is an important source of
IL -6 , and portal vein IL-6 levels relate to arterial Creactive protein levels [44]. Nevertheless, despite observed links between visceral adiposity and systemic inflammation, no studies addressed the question regarding adipose tissue contribution to systemic inflammation in patients with COPD.

\subsubsection{A Novel Concept of Systemic Inflammation Origin in} COPD: Dependence on Pulmonary Impairment and Obesity. Three lines of evidence, that is, experimental studies, studies in humans involving measurements of lung vasculature permeability, and treatment studies in COPD with inhaled corticosteroids support the concept that pulmonary inflammation is the prevailing mechanism contributing to systemic inflammation in such patients. Nevertheless, when interpreting the above studies, one crucial factor needs to be taken into account: the severity of lung structure/function impairment. Since highest permeability of pulmonary vessels occurs in subjects with the lowest $\mathrm{FEV}_{1}$ [36], and inhaled corticosteroids reduced systemic inflammation in patients with at least moderate degree of bronchial obstruction $[42,43]$, the mechanism of inflammatory proteins spillover from the pulmonary to the systemic compartment is likely to have the highest relevance in patients with more pronounced pulmonary impairment. Nevertheless, lung-to-blood translocation of inflammatory mediators may not be prominent in subjects with mild form of the disease. In contrast, the prevalence and degree of obesity are significantly higher in patients with mild compared to more advanced COPD (see further) [9, 45]. Therefore, it is reasonable to assume that obesity-related adipose tissue inflammation likely represents a significant contributor to the overall systemic inflammatory profile in patients with mild form of the disease with concurrent obesity (Figure 1). The hypothesis that adipose tissue may contribute to the overall systemic inflammatory phenotype in patients with early stages COPD with obesity or relative abundant fat mass is novel [10]. Therefore, we discuss further essential issues related to body composition in COPD, endocrine function of adipose tissue, and the role of hypoxia in adipose tissue inflammation.

\section{Body Composition in COPD}

In patients with COPD, obesity is characterized by an absolute abundance of fat mass (FM), similar to other diseases associated with excessive adiposity (i.e., metabolic syndrome, hypercorticism, etc.). The prevalence of abdominal obesity measured by waist circumference is almost twice as high as in age- and sex-matched controls [46]. Patients with normal body mass index (BMI) display either physiological or reduced ratio of fat-free mass (FFM) to FM. Importantly, selective wasting of FFM (i.e., loss of muscle mass) occurs in about $10 \%$ of COPD patients with normal BMI, resulting in a relative or absolute increase in FM [47-49]. Nevertheless, cachectic patients with COPD experiencing reductions in their body weight below the physiological range suffer from both loss of FFM in association with the loss of FM [50]. 

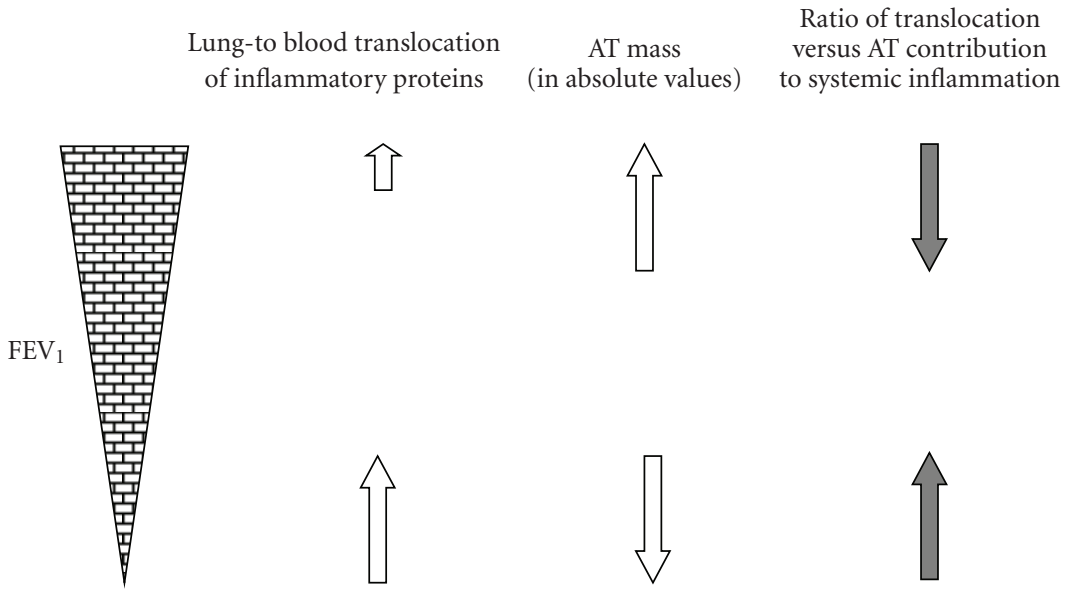

FIGURE 1: Concept of differential contribution of lung-to-blood translocation of inflammatory proteins versus adipose tissue inflammation to the overall systemic inflammatory phenotype in COPD. We suggest that in patients with mild COPD and concurrent obesity, adipose tissue (AT) is the key contributor to systemic inflammation, whereas in those with severe COPD, lung-to-blood translocation of inflammatory proteins plays the major role.

4.1. Epidemiology of Obesity in COPD. Obesity has emerged as an important risk factor for respiratory disorders, and a link between obesity and/or metabolic syndrome and COPD is increasingly recognized $[10,51,52]$. The prevalence of obesity is the highest among patients with milder forms of the disease (GOLD Stages 1 and 2), and the lowest in patients with the most severe lung function impairment in Stage $4[8,45]$. Marquis et al. [46] demonstrated the presence of one or more components of the metabolic syndrome in almost $50 \%$ of COPD patients. Furthermore, in a recent population-based survey that involved 7,358 adults aged $\geq 50$ years, the risk of metabolic syndrome was higher in those with airflow obstruction compared to those without [53]. In the Tucson prospective cohort study, prevalence of BMI $\geq 28 \mathrm{~kg} / \mathrm{m}^{2}$ was significantly higher in patients with chronic bronchitis compared to controls (25 versus 16\%) [54]. Furthermore, two large epidemiological studies identified increased prevalence of obesity among patients with COPD than in the general population. In Northern California (USA), $54 \%$ of patients with COPD were obese and had BMI $\geq 30 \mathrm{~kg} / \mathrm{m}^{2}$ compared to $20-24 \%$ prevalence of obesity in the general population [55]. In the European cohort of COPD patients in Netherlands, obesity prevalence of $18 \%$ was reported [9] in contrast to only $10-12 \%$ prevalence in the general cohort of residents in the same region [55]. So far the largest and the most convincing study examined 121,965 men and women in France, and demonstrated an independent association between lung function impairment and the metabolic syndrome after correction for age, sex, smoking status, BMI, physical activity, and cardiovascular disease history [52]. Interestingly, abdominal obesity was the strongest predictor of lung function impairment in both men and women [52]. Similar associations between central obesity and airflow obstruction that were independent of smoking status were observed recently also in a large Chinese cohort [53].
4.2. Putative Mechanisms. The nature of the association between obesity and COPD has not been fully elucidated [51]. Nevertheless, several pathogenetic mechanisms may link these two conditions (Figure 2). First, as indicated before, systemic inflammatory syndrome is a hallmark of both conditions obesity and COPD. Second, reduced physical inactivity is frequently observed in patients with COPD [56]. On one hand, airflow limitation limits exercise performance and reduces physical activity, and consequently increases propensity to weight gain in patients with COPD. On the other hand, obesity further compromises pulmonary functions [10], and therefore represents additional factor contributing to the patient's inactivity (Figure 2). Importantly, a recent study by Watz et al. [57] demonstrated that the coexisting obesity and metabolic syndrome are associated with both increases in systemic inflammatory markers and reduced physical activity independently of lung function impairment. In reverse, regular physical activity modifies smoking-related lung function decline and development of COPD [58].

4.3. Clinical Implications of Obesity in COPD. High adiposity and fat tissue accumulation impair pulmonary functions and exercise performance $[50,51,55]$; this topic has been recently extensively reviewed [10]. Additionally, obesity and the presence of metabolic syndrome are related to increased insulin resistance in overweight and obese COPD patients $[59,60]$. The study by Bolton et al. [59] suggests that insulin resistance is aggravated by both, high BMI and increases in circulatory inflammatory mediators such as IL- 6 in these patients. Indeed, inflammatory mediators TNF- $\alpha$, IL-6, and leptin were significantly higher while plasma adiponectin levels were reduced in the presence of excess weight in COPD patients [51].

In patients with COPD, the relationship between body weight and mortality risk is not unidirectional. In earlier 


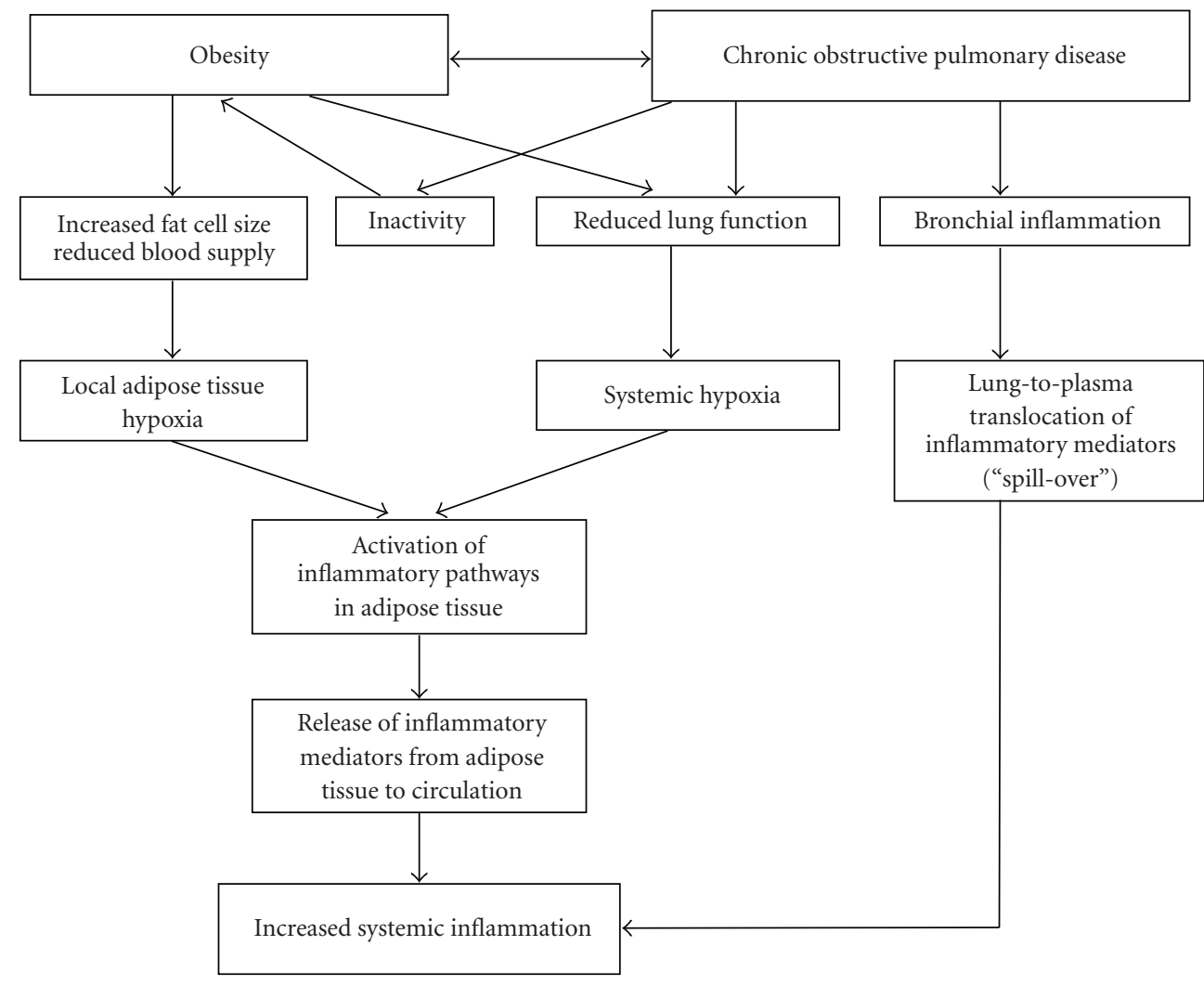

FIGURE 2: Proposed mechanistic links between the combined effects of obesity-related local adipose tissue hypoxia, reduced lung functionrelated systemic hypoxia, and bronchial inflammation-related increased lung-to-plasma translocation of inflammatory mediators on systemic inflammatory profile in patients with COPD.

stages of this disease, low-grade systemic inflammation related to visceral obesity likely represents one of the key factors contributing to increased risk of comorbidities such as cardiovascular complications and type 2 diabetes. Therefore, similar to the metabolic syndrome and type 2 diabetes, obesity in COPD patients with GOLD Stages 1 and 2 severity may contribute to their increased cardiovascular and allcause mortality [10]. In contrast, the relative mortality risk is reduced in overweight patients with severely deteriorated lung functions in GOLD Stages 3 and $4[61,62]$, a condition described as "obesity paradox". Of note, obesity paradox has been repeatedly reported not only in severe COPD but also in other serious conditions associated with wasting and high mortality risk such as malignancies [63], chronic heart failure [64], renal failure [65], and AIDS [66].

\section{Inflammatory Mediators and Adipose Tissue}

5.1. Adipose Tissue as an Endocrine Organ. Adipose tissue is currently viewed as a highly dynamic endocrine organ that is involved in a wide range of metabolic processes [6770]. Within adipose tissue, adipocytes, macrophages, and endothelial cells synthesize and release a large number of a diverse group of proteins involved in several functional categories such as inflammation and acute-phase response, immunity, insulin sensitivity, angiogenesis, blood pressure control, lipid metabolism and hemostasis [69], recommend that the term "adipokine" be universally used to describe proteins synthesized by and secreted from adipocytes. Adipocytes express and secrete a variety of adipokines including cytokines, growth factors, adiponectin, resistin, adipsin, leptin, acylation stimulating protein, plasminogen activator inhibitor-1 (PAI-1), lipoprotein lipase, and components of the renin-angiotensin system which may exert local (autocrine/paracrine) and systemic (endocrine) effects [67-69].

5.2. TNF- $\alpha$ and Interleukins. Marked increases in the expression of TNF- $\alpha$ were identified in obese mouse models [71], and were linked to obesity and insulin resistance. Nevertheless, although TNF- $\alpha$ secretion is increased in enlarged adipocytes, TNF- $\alpha$ per se has proapoptotic properties [72]. A number of adipocyte-abundant genes (GLUT4, hormone sensitive lipase, long-chain fatty acylCoA synthase, adipocyte complement-related protein of $30 \mathrm{kDa}$, and transcription factors CCAT/enhancer binding protein-alpha, receptor retinoid $\mathrm{X}$ receptor-alpha, and PPAR $\gamma$ ) are significantly down-regulated by TNF- $\alpha$ [73]. Correspondingly, exposure of adipocytes to TNF- $\alpha$ results in reduced GLUT4 and several insulin signaling proteins levels (insulin receptor, insulin receptor substrate 1 , and protein kinase (B). NF- $\kappa$ B is activated within 15 minutes of TNF- $\alpha$ 
addition. The absence of NF- $\kappa \mathrm{B}$ activation leads to a release of more than $98 \%$ of the genes normally suppressed by TNF$\alpha$, and, on the other hand, to a suppression of $60-70 \%$ of the genes whose expression is physiologically induced by TNF- $\alpha$ [73]. Taken together, changes in adipocyte gene expression induced by TNF- $\alpha$ could lead to insulin resistance, and $\mathrm{NF}-\kappa \mathrm{B}$ seems to be an obligatory mediator of most of these TNF- $\alpha$ responses.

As much as a third of total circulating concentrations of IL- 6 has been estimated to originate from adipose tissue [74], and circulatory concentrations of IL-6 were shown to be related to BMI. TNF- $\alpha$ is a potent stimulus for IL-6 synthesis in adipocytes: a 60-fold increase in IL-6 production in differentiated 3T3-L1 adipocytes was observed after TNF- $\alpha$ exposure [75], in association with enhanced shedding of sTNF-RII receptors from the adipose tissue [74]. IL-6 decreases adipose tissue LPL activity, and has been implicated in lipolysis and fat depletion taking place during cancer cachexia [76]. Like TNF- $\alpha$, IL-6 has potent effects on adipose tissue, as evidenced by the fact that neutralization of this cytokine decreases progressive loss of adipose tissue during cachexia [77].

IL-8 is also highly expressed and produced in human adipocyte tissue, and similarly to IL- 6 , TNF- $\alpha$ represents a potent stimulus for the production and release of IL8 from adipocytes. In obese subjects, positive correlations between circulating TNF- $\alpha$ and IL- 8 were demonstrated [78]. Nevertheless, no data are available either on the potential link between adipose tissue expression of IL- 6 and IL-8, and their respective circulatory levels in patients with COPD.

5.3. Leptin and Adiponectin. Leptin, a protein synthesized by white adipose tissue and encoded by the $o b$ gene, plays an important role in energy balance. Growing body of evidence suggests that leptin may have an important role in upregulating the inflammatory system: not only does TNF$\alpha$ promote release of leptin from adipose tissue [79] but leptin may per se up-regulate expression of proinflammatory cytokines [80]. Plasma leptin correlates with BMI, and weight loss reduces its circulatory concentrations in a variety of human disorders associated with obesity [81]. Nevertheless, only a few studies analyzed associations between lung function impairment and circulatory leptin. In 2808 nonobese individuals, Sin and Man [82] demonstrated that those with impaired lung function have raised serum leptin levels. In another study, Creutzberg et al. [83] documented impairments of normal leptin feedback mechanisms during exacerbations of COPD suggesting that elevated leptin concentrations might represent an up-regulation of leptin mRNA in adipose tissue resulting in an enhanced leptin production in such patients. So far the only adipocytederived hormone that is known to exert anti-inflammatory effects is adiponectin, and its expression is reduced in obesity $[84,85]$. Acute exacerbations of COPD are associated with increases in serum leptin levels and the leptin/adiponectin ratio, and these elevations were related to serum IL-6 and TNF- $\alpha$ [84]. In turn, adiponectin levels increased at resolution of COPD exacerbation [86].
5.4. Adipocyte Tissue Hypoxia in Obesity: Effects on Inflammatory Mediators. The expression and/or secretion of inflammatory molecules are increased in the adipose tissue of obese insulin-resistant individuals. In contrast to small adipocytes, enlarged adipocytes in conditions associated with obesity express proinflammatory and anti-inflammatory factors with a shift towards dominance of proinflammatory adipokines [87]. Elevated levels of IL-6 were detected in obese women, and were reduced after weight loss [88]. In addition, increased expression of inflammatory mediators such as TNF- $\alpha$ [71, 89], PAI-1 [90], and leptin [89] was detected in human obesity.

Chronic low-grade adipose tissue inflammation in obesity may represent a specific response to relative hypoxia of adipocytes [69]. Several factors may contribute to cell hypoxia within adipose tissue in association with high adiposity: (a) blood flow per unit adipose tissue mass is reduced in obese humans [91] resulting in decreased blood supply to the tissue; (b) large adipocytes are further from the vasculature than the normal diffusion distance for $\mathrm{O}_{2}(150$ versus $100 \mu \mathrm{m})$. Therefore, clusters of adipocytes become distant from the vasculature as cell size increases resulting in their relative hypoxia and increased inflammatory response which serves to increase blood flow and to stimulate angiogenesis [69].

Adipocyte tissue hypoxia has detrimental effects on cell metabolism and function, as evidenced by studies in vitro and animal models. Studies in vitro have shown that hypoxia results in enhanced TNF- $\alpha$ production, increased expression of PAI-1, and reduced adiponectin and peroxisome proliferator-activated receptor gamma (PPAR $\gamma)$ expression [92, 93]. In addition, animal models in obese mice demonstrated occurrence of hypoxia in adipose tissue in association with increased expression of proinflammatory adipokines [93]. Hypoxia-induced factor (HIF)$1 \alpha$ represents the key hypoxia-sensing protein in most tissues. Not only does it play a central role by signaling the presence of hypoxia to the transcriptional systems in the nuclei of all cells but it also activates a number of target genes whose products are involved in inflammatory responses such as IL-6, TNF- $\alpha$, macrophage migration inhibitory factor, vascular endothelial growth factor, tissue inhibitor of metalloproteinases-1, and monocyte chemotactic protein $[94,95]$. Transcription factors such as NF- $\kappa \mathrm{B}$ and sterol regulatory element-binding protein (SREBP) are downstream molecules of HIF- $1 \alpha$ signaling pathways that in turn regulate production of TNF- $\alpha$ and IL-6 [96]. The number of identified genes with demonstrated responsiveness to HIF$1 \alpha$ is steadily growing, and to date more than 70 genes have been described as targets of this molecule [94]. These genes encode proteins involved in energy metabolism, cell proliferation, apoptosis, and angiogenesis [97-99]. Genes whose expression is up- or down-regulated in adipocytes by hypoxia have been recently extensively reviewed elsewhere [100].

5.5. Systemic Hypoxia in Respiratory Disorders. Significant inverse relationships were observed between $\mathrm{PaO}_{2}$ and circulating TNF- $\alpha$ and staff-R levels in patients with COPD [101]. 
Lipid peroxidation products are increased, and antioxidative enzymes are reduced in the circulation of patients with COPD at rest and during exercise [102], and increase even further during exacerbations of the disease [103]. In addition, an association between markers of systemic inflammation and markers of oxidative stress during exacerbations of COPD was described [103]. However, no studies were undertaken until now to analyze adipose tissue inflammation in patients either with stable COPD or during the disease exacerbations. It is reasonable to hypothesize that increases in proinflammatory cytokine expression and their release from adipose tissue to the systemic compartment occur not only in response to local obesity-related tissue hypoxia but also in response to systemic hypoxia resulting from reduced pulmonary functions. Nevertheless, it is unclear whether systemic hypoxia exerts additional or multiplicative effects on adipose tissue in patients with COPD and concurrent obesity. Interestingly, similar uncertainties dwell in the search for the potential synergistic negative effects of obesity and obstructive sleep apnea, a condition characterized by repetitive cessation of breathing during sleep and intermittent hypoxia [104]. While the association between sleep apnea and systemic inflammation has been repeatedly reported [105-107], and the effects of intermittent hypoxia on metabolic derangements and systemic inflammation have been documented in animal models [108-111], the topic of adipose tissue response to intermittent hypoxia in patients with sleep apnea is still unexplored. Similarly, the study of the effects of chronic systemic hypoxia related to COPD on adipocyte structure and function represents a major research challenge.

5.6. Cross-Talk between Adipocyte Tissue and Lungs: Search for Evidence. Epidemiological evidence that links COPD to obesity and metabolic syndrome, in association with pleiotropic character of most inflammatory mediators, suggests that a physiologically and clinically relevant crosstalk might exist between the lungs and adipocyte tissue. Although such concept has not been yet directly studied in detail, several findings suggest that this hypothesis worth further exploration. First, receptors of two typical adipocytederived cytokines, leptin, and adiponectin, are expressed in peripheral tissues including lung $[112,113]$. Interestingly, increased leptin expression in bronchial mucosa was observed in patients with COPD, in association with airway inflammation and airflow obstruction [112, 114]. Moreover, leptin receptor polymorphisms were linked to the decline in pulmonary functions, and leptin receptor is considered a novel candidate gene for COPD [115], whereas adiponectin may attenuate allergen-induced airway inflammation and hyperresponsiveness suggesting its potential protective role within the airways [116]. In turn, expression of SP-D, the protein that was originally thought to be restricted to the pulmonary compartment, was recently located in both epithelial cells of multiple mucosal surfaces and in endothelial cells [117]. Interestingly, genetic variations in serum SP-D and BMI are correlated [118], and a negative association between serum SP-D and obesity measures was observed in humans [117]. Nevertheless, the nature of the association remains unknown and additional research is needed in this field.

\section{Conclusion and Future Perspectives}

A new paradigm may emerge in the approach to analyze key question whether adipose tissue contributes to systemic inflammation in such disorders that are associated with both, obesity and systemic hypoxia. Approaching this question is relevant in at least two highly prevalent conditions in human respirology, that is, COPD and sleep apnea. On one hand, in patients with COPD, systemic inflammatory phenotype likely reflects inflammation in the lungs, that is, results from lung-to-plasma spillover of inflammatory mediators. On the other hand, however, obesity-related hypoxia evokes local inflammatory response within adipose tissue per se, and systemic hypoxia likely contributes to the adipose tissue inflammation. If so, elevated circulating levels of inflammation-related proteins may reflect also spillover from the adipose tissue to the systemic circulation in patients with COPD and concurrent obesity. Taken together, although current evidence suggests that lung inflammation and spillover of inflammatory mediators to the systemic compartment represent key mechanisms of systemic inflammation in COPD, both lung and adipose tissue origin of increased levels of circulatory inflammatory proteins likely coincide in some patients. The relative impact of the two mechanisms may depend on at least three factors: severity of pulmonary impairment (i.e., the rate of translocation of inflammatory mediators from the lungs to the systemic circulation), the degree of obesity-related adipose tissue hypoxia, and the severity of systemic hypoxia due to reduced pulmonary functions (Figure 1). Future studies are urgently needed to address these questions.

Ultimately, the crucial task is to develop novel therapies that would be effective in reductions in systemic inflammation, and in reductions of mortality in patients with COPD. In this regard, anti-inflammatory drugs, adipokines, hormones, and appetite stimulants are in the center of research interest. Effective anti-inflammatory therapies carry the potential that they will not only suppress systemic inflammation but also treat comorbid conditions and systemic manifestations of the disease [3]. Future translational and clinical research overlapping respirology and metabolism with the aim to unravel the role of adipose tissue in COPDassociated comorbidities is highly warranted.

\section{Acknowledgments}

The work has been supported by the project "Centre for Excellent Research of Atherosclerosis and its Complications-Myocardial Infarction and Stroke", Operational Program of Research and Development financed by European Fund for Regional Development, Contract no: 005/2009/2.1/OPR\&D (50\%), and Slovak Research and Development Agency under the contract no. APVV-0122$06(50 \%)$, Slovakia. The author was a visiting scientist at the James Hogg iCAPTURE Center, Vancouver, Canada. She 
expresses special thanks to dr. Don D. Sin for his input and helpful discussions.

\section{References}

[1] R. A. Pauwels, A. S. Buist, P. M. A. Calverley, C. R. Jenkins, and S. S. Hurd, "Global strategy for the diagnosis, management, and prevention of chronic obstructive pulmonary disease: NHLBI/WHO global initiative for chronic obstructive lung disease (GOLD) workshop summary," American Journal of Respiratory and Critical Care Medicine, vol. 163, no. 5, pp. 1256-1276, 2001.

[2] K. F. Rabe, S. Hurd, A. Anzueto, et al., "Global strategy for the diagnosis, management, and prevention of chronic obstructive pulmonary disease: GOLD executive summary," American Journal of Respiratory and Critical Care Medicine, vol. 176, no. 6, pp. 532-555, 2007.

[3] P. J. Barnes and B. R. Celli, "Systemic manifestations and comorbidities of COPD," European Respiratory Journal, vol. 33, no. 5, pp. 1165-1185, 2009.

[4] E. F. M. Wouters, "Local and systemic inflammation in chronic obstructive pulmonary disease," Proceedings of the American Thoracic Society, vol. 2, no. 1, pp. 26-33, 2005.

[5] L. M. Fabbri and K. F. Rabe, "Multiple chronic diseases," in Proceedings of a European Respiratory Society Research Seminar, Rome, Italy, February 2007.

[6] L. P. McGarvey, M. John, J. A. Anderson, M. Zvarich, and R. A. Wise, "Ascertainment of cause-specific mortality in COPD: operations of the TORCH Clinical Endpoint Committee," Thorax, vol. 62, no. 5, pp. 411-415, 2007.

[7] H. Bruunsgaard and B. K. Pedersen, "Age-related inflammatory cytokines and disease," Immunology and Allergy Clinics of North America, vol. 23, no. 1, pp. 15-39, 2003.

[8] D. D. Sin and S. F. Paul Man, "Why are patients with chronic obstructive pulmonary disease at increased risk of cardiovascular diseases? The potential role of systemic inflammation in chronic obstructive pulmonary disease," Circulation, vol. 107, no. 11, pp. 1514-1519, 2003.

[9] L. M. G. Steuten, E. C. Creutzberg, H. J. M. Vrijhoef, and E. F. Wouters, "COPD as a multicomponent disease: inventory of dyspnoea, underweight, obesity and fat free mass depletion in primary care," Primary Care Respiratory Journal, vol. 15, no. 2, pp. 84-91, 2006.

[10] F. M. E. Franssen, D. E. O’Donnell, G. H. Goossens, E. E. Blaak, and A. M. W. J. Schols, "Obesity and the lung: 5. Obesity and COPD," Thorax, vol. 63, no. 12, pp. 1110-1117, 2008.

[11] L. M. Fabbri and K. F. Rabe, "From COPD to chronic systemic inflammatory syndrome?" The Lancet, vol. 370, no. 9589, pp. 797-799, 2007.

[12] M. J. Sevenoaks and R. A. Stockley, "Chronic obstructive pulmonary disease, inflammation and co-morbidity: a common inflammatory phenotype?" Respiratory Research, vol. 7, article 70, 2006.

[13] D. M. Mannino, G. Watt, D. Hole, et al., "The natural history of chronic obstructive pulmonary disease," European Respiratory Journal, vol. 27, no. 3, pp. 627-643, 2006.

[14] M. A. Dentener, E. C. Creutzberg, A. M. Schols, et al., "Systematic anti-inflammatory mediators in COPD: increase in soluble interleukin 1 receptor II during treatment of exacerbations," Thorax, vol. 56, pp. 721-726, 2001.

[15] D. M. Mannino, E. S. Ford, and S. C. Redd, "Obstructive and restrictive lung disease and markers of inflammation: data from the third national health and nutrition examination," American Journal of Medicine, vol. 114, no. 9, pp. 758-762, 2003.

[16] A. M. W. J. Schols, J. Slangen, L. Volovics, and E. F. M. Wouters, "Weight loss is a reversible factor in the prognosis of chronic obstructive pulmonary disease," American Journal of Respiratory and Critical Care Medicine, vol. 157, no. 6, pp. 1791-1797, 1998.

[17] C. Landbo, E. Prescott, P. Lange, J. Vestbo, and T. P. Almdal, "Prognostic value of nutritional status in chronic obstructive pulmonary disease," American Journal of Respiratory and Critical Care Medicine, vol. 160, no. 6, pp. 1856-1861, 1999.

[18] E. Prescott, T. Almdal, K. L. Mikkelsen, C. L. Tofteng, J. Vestbo, and P. Lange, "Prognostic value of weight change in chronic obstructive pulmonary disease: results from the Copenhagen City Heart Study," European Respiratory Journal, vol. 20, no. 3, pp. 539-544, 2002.

[19] F. Koehler, W. Doehner, S. Hoernig, C. Witt, S. D. Anker, and M. John, "Anorexia in chronic obstructive pulmonary disease: association to cachexia and hormonal derangement," International Journal of Cardiology, vol. 119, no. 1, pp. 83-89, 2007.

[20] A. M. W. Petersen, M. Penkowa, M. Iversen, et al., "Elevated levels of IL-18 in plasma and skeletal muscle in chronic obstructive pulmonary disease," Lung, vol. 185, no. 3, pp. 161-171, 2007.

[21] O. B. Margretardottir, S. J. Thorleifsson, G. Gudmundsson, et al., "Hypertension, systemic inflammation and body weight in relation to lung function impairment: an epidemiological study," Journal of Chronic Obstructive Pulmonary Disease, vol. 6, no. 4, pp. 250-255, 2009.

[22] A. F. Connors Jr., N. V. Dawson, C. Thomas, et al., "Outcomes following acute exacerbation of severe chronic obstructive lung disease. The SUPPORT investigators (Study to understand prognoses and preferences for outcomes and risks of treatments)," American Journal of Respiratory and Critical Care Medicine, vol. 154, no. 4, pp. 959-967, 1996.

[23] U. Kolsum, K. Roy, C. Starkey, et al., "The repeatability of interleukin-6, tumor necrosis factor-alpha, and C-reactive protein in COPD patients over one year," Journal of Chronic Obstructive Pulmonary Disease, vol. 4, no. 1, pp. 149-156, 2009.

[24] L. Watson, J. M. Vonk, C. G. Löfdahl, et al., "Predictors of lung function and its decline in mild to moderate COPD in association with gender: results from the Euroscop study," Respiratory Medicine, vol. 100, no. 4, pp. 746-753, 2006.

[25] R. Kessler, M. Faller, G. Fourgaut, B. Mennecier, and E. Weitzenblum, "Predictive factors of hospitalization for acute exacerbation in a series of 64 patients with chronic obstructive pulmonary disease," American Journal of Respiratory and Critical Care Medicine, vol. 159, no. 1, pp. 158-164, 1999.

[26] M. Vitacca, E. Clini, R. Porta, K. Foglio, and N. Ambrosino, "Acute exacerbations in patients with COPD: predictors of need for mechanical ventilation," European Respiratory Journal, vol. 9, no. 7, pp. 1487-1493, 1996.

[27] D. Justo, S. Lachmi, N. Saar, et al., "C-reactive protein velocity following antibiotics in patients with chronic obstructive pulmonary disease exacerbation and community acquired pneumonia," European Journal of Internal Medicine, vol. 20, no. 5, pp. 518-521, 2009.

[28] J. P. de Torres, E. Cordoba-Lanus, C. Lopez-Aguillar, et al., "C-reactive protein levels and clinically important predictive outcomes in stable COPD patients," European Respiratory Journal, vol. 27, no. 5, pp. 902-907, 2006. 
[29] S. F. P. Man, J. E. Connett, N. R. Anthonisen, R. A. Wise, D. P. Tashkin, and D. D. Sin, "C-reactive protein and mortality in mild to moderate chronic obstructive pulmonary disease," Thorax, vol. 61, no. 10, pp. 849-853, 2006.

[30] J. H. Vernooy, M. Kücükaycan, J. A. Jacobs, et al., "Local and systemic inflammation in patients with chronic obstructive pulmonary disease: soluble tumor necrosis factor receptors are increased in sputum," American Journal of Respiratory and Critical Care Medicine, vol. 166, no. 9, pp. 1218-1224, 2002.

[31] M. Zeng, Y. Wen, L.-Y. Liu, H. Wang, K.-P. Guan, and X. Huang, "Role of TNF-alpha, sTNF-R55 and sTNF-R75 in inflammation of acute exacerbations of chronic obstructive pulmonary disease," Respiration, vol. 78, no. 4, pp. 399-403, 2009.

[32] K. F. Chung and I. M. Adcock, "Multifaceted mechanisms in COPD: inflammation, imunity, and tissue repair and destruction," European Respiratory Journal, vol. 31, pp. 1334 1356, 2008.

[33] S. F. Van Eeden and D. D. Sin, "Chronic obstructive pulmonary disease: a chronic systemic inflammatory disease," Respiration, vol. 75, no. 2, pp. 224-238, 2008.

[34] V. Kim, T. J. Rogers, and G. J. Criner, "New concepts in the pathobiology of chronic obstructive pulmonary disease," Proceedings of the American Thoracic Society, vol. 5, no. 4, pp. 478-485, 2008.

[35] S. M. Kennedy, R. K. Elwood, and B. J. R. Wiggs, "Increased airway mucosal permeability of smokers. Relationship to airway reactivity," American Review of Respiratory Disease, vol. 129, no. 1, pp. 143-148, 1984.

[36] P. Wollmer and E. Evander, "Biphasic pulmonary clearance of 99mTc-DTPA in smokers," Clinical Physiology, vol. 14, no. 5, pp. 547-559, 1994.

[37] D. S. Olivera, S. E. Boggs, C. Beenhouwer, J. Aden, and C. Knall, "Cellular mechanisms of mainstream cigarette smokeinduced lung epithelial tight junction permeability changes in vitro," Inhalation Toxicology, vol. 19, no. 1, pp. 13-22, 2007.

[38] B. Schmekel, L. Borgstrom, and P. Wollmer, "Difference in pulmonary absorption of inhaled terbutaline in healthy smokers and non-smokers," Thorax, vol. 46, no. 4, pp. 225228, 1991.

[39] M. Fujita, J. M. Shannon, H. Ouchi, D. R. Voelker, Y. Nakanishi, and R. J. Mason, "Serum surfactant protein D is increased in acute and chronic inflammation in mice," Cytokine, vol. 31, no. 1, pp. 25-33, 2005.

[40] E. Tamagawa, K. Suda, Y. Wei, et al., "Endotoxin-induced translocation of interleukin-6 from lungs to the systemic circulation," Innate Immunity, vol. 15, no. 4, pp. 251-258, 2009.

[41] S.-H. Chou, Y.-W. Chen, H.-Y. Chuang, E.-L. Kao, and M.-F. Huang, "Alveolar-capillary membrane permeability for early prediction of response of inhaled steroid on patients with chronic obstructive pulmonary disease," Journal of Clinical Pharmacy and Therapeutics, vol. 31, no. 4, pp. 363-368, 2006.

[42] S. F. P. Man, Z. Xuekui, R. Vessey, et al., "The effects of inhaled and oral corticosteroids on serum inflammatory biomarkers in COPD: an exploratory study," Therapeutic Advances in Respiratory Disease, vol. 3, no. 2, pp. 73-80, 2009.

[43] S. A. Antoniu, "Inhaled corticosteroids in COPD: systemic effects of a local therapy?" Expert Opinion on Pharmacotherapy, vol. 9, pp. 3271-3273, 2008.

[44] L. Fontana, J. C. Eagon, M. E. Trujillo, P. E. Scherer, and S. Klein, "Visceral fat adipokine secretion is associated with systemic inflammation in obese humans," Diabetes, vol. 56, no. 4, pp. 1010-1013, 2007.
[45] M. Poulain, M. Doucet, V. Drapeau, et al., "Metabolic and inflammatory profile in obese patients with chronic obstructive pulmonary disease," Chronic Respiratory Disease, vol. 5, no. 1, pp. 35-41, 2008.

[46] K. Marquis, F. Maltais, V. Duguay, et al., "The metabolic syndrome in patients with chronic obstructive pulmonary disease," Journal of Cardiopulmonary Rehabilitation, vol. 25, no. 4, pp. 226-232, 2005.

[47] J. Vestbo, E. Prescott, T. Almdal, et al., "Body mass, fatfree body mass, and prognosis in patients with chronic obstructive pulmonary disease from a random population sample: findings from the Copenhagen City Heart Study," American Journal of Respiratory and Critical Care Medicine, vol. 173, no. 1, pp. 79-83, 2006.

[48] M. P. K. J. Engelen, A. M. W. J. Schols, R. J. S. Lamers, and E. F. M. Wouters, "Different patterns of chronic tissue wasting among patients with chronic obstructive pulmonary disease," Clinical Nutrition, vol. 18, no. 5, pp. 275-280, 1999.

[49] G. Sergi, A. Coin, S. Marin, et al., "Body composition and resting energy expenditure in elderly male patients with chronic obstructive pulmonary disease," Respiratory Medicine, vol. 100, no. 11, pp. 1918-1924, 2006.

[50] X. Liu, Y. Ji, J. Chen, S. Li, and F. Luo, "Circulating visfatin in chronic obstructive pulmonary disease," Nutrition, vol. 25, no. 4, pp. 373-378, 2009.

[51] M. Poulain, M. Doucet, G. C. Major, et al., "The effect of obesity on chronic respiratory diseases: pathophysiology and therapeutic strategies," Canadian Medical Association Journal, vol. 174, no. 9, pp. 1293-1299, 2006.

[52] N. Leone, D. Courbon, F. Thomas, et al., "Lung function impairment and metabolic syndrome the critical role of abdominal obesity," American Journal of Respiratory and Critical Care Medicine, vol. 179, no. 6, pp. 509-516, 2009.

[53] K.-B. H. Lam, R. E. Jordan, C. Q. Jiang, et al., "Airflow obstruction and metabolic syndrome: the Guangzhou Biobank Cohort Study," European Respiratory Journal, vol. 35, no. 2, pp. 317-323, 2010.

[54] S. Guerra, D. L. Sherrill, A. Bobadilla, F. D. Martinez, and R. A. Barbee, "The relation of body mass index to asthma, chronic bronchitis, and emphysema," Chest, vol. 122, no. 4, pp. 1256-1263, 2002.

[55] D. F. Schokker, T. L. S. Visscher, A. C. J. Nooyens, M. A. Van Baak, and J. C. Seidell, "Prevalence of overweight and obesity in the Netherlands," Obesity Reviews, vol. 8, no. 2, pp. 101$108,2007$.

[56] N. H. T. ten Hacken, "Physical inactivity and obesity: relation to asthma and chronic obstructive pulmonary disease?" Proceedings of the American Thoracic Society, vol. 6, no. 8, pp. 663-667, 2009.

[57] H. Watz, B. Waschki, A. Kirsten, et al., "The metabolic syndrome in patients with chronic bronchitis and COPD: frequency and associated consequences for systemic inflammation and physical inactivity," Chest, vol. 136, no. 4, pp. 1039-1046, 2009.

[58] J. Garcia-Aymerich, P. Lange, M. Benet, P. Schnohr, and J. M. Antó, "Regular physical activity modifies smokingrelated lung function decline and reduces risk of chronic obstructive pulmonary disease: a population-based cohort study," American Journal of Respiratory and Critical Care Medicine, vol. 175, no. 5, pp. 458-463, 2007.

[59] C. E. Bolton, M. Evans, A. A. Ionescu, et al., "Insulin resistance and inflammation: a further systemic complication of COPD," Journal of Chronic Obstructive Pulmonary Disease, vol. 4, no. 2, pp. 121-126, 2007. 
[60] F. Koehler, W. Doehner, S. Hoernig, C. Witt, S. D. Anker, and M. John, "Anorexia in chronic obstructive pulmonary disease: association to cachexia and hormonal derangement," International Journal of Cardiology, vol. 119, no. 1, pp. 83-89, 2007.

[61] C. Landbo, E. Prescott, P. Lange, J. Vestbo, and T. P. Almdal, "Prognostic value of nutritional status in chronic obstructive pulmonary disease," American Journal of Respiratory and Critical Care Medicine, vol. 160, no. 6, pp. 1856-1861, 1999.

[62] J. Vestbo, E. Prescott, T. Almdal, et al., "Body mass, fatfree body mass, and prognosis in patients with chronic obstructive pulmonary disease from a random population sample: findings from the Copenhagen City Heart Study," American Journal of Respiratory and Critical Care Medicine, vol. 173, no. 1, pp. 79-83, 2006.

[63] M. J. Tisdale, "Mechanisms of cancer cachexia," Physiological Reviews, vol. 89, no. 2, pp. 381-410, 2009.

[64] A. Miján-de-la-Torre, "Recent insights on chronic heart failure, cachexia and nutrition," Current Opinion in Clinical Nutrition and Metabolic Care, vol. 12, no. 3, pp. 251-257, 2009.

[65] M. Fleet, F. Osman, R. Komaragiri, A. Fritz, and D. S. C. Raj, "Protein catabolism in advanced renal disease: role of cytokines," Clinical Nephrology, vol. 70, no. 2, pp. 91-100, 2008.

[66] M. Gelato, M. McNurlan, and E. Freedland, "Role of recombinant human growth hormone in HIV-associated wasting and cachexia: pathophysiology and rationale for treatment," Clinical Therapeutics, vol. 29, no. 11, pp. 22692288, 2007.

[67] P. Trayhurn and J. H. Beattie, "Physiological role of adipose tissue: white adipose tissue as an endocrine and secretory organ," Proceedings of the Nutrition Society, vol. 60, pp. 329339, 2001.

[68] E. E. Kershaw and J. S. Flier, "Adipose tissue as an endocrine organ," Journal of Clinical Endocrinology and Metabolism, vol. 89, no. 6, pp. 2548-2556, 2004.

[69] P. Trayhurn and I. S. Wood, "Adipokines: inflammation and the pleiotropic role of white adipose tissue," British Journal of Nutrition, vol. 92, no. 3, pp. 347-355, 2004.

[70] V. Mohamed-Ali, S. Goodrick, A. Rawesh, et al., "Subcutaneous adipose tissue releases interleukin-6, but not tumor necrosis factor-alpha, in vivo," Journal of Clinical Endocrinology and Metabolism, vol. 82, no. 12, pp. 41964200, 1997.

[71] G. S. Hotamisligil, P. Arner, J. F. Caro, R. L. Atkinson, and B. M. Spiegelman, "Increased adipose tissue expression of tumor necrosis factor-alpha in human obesity and insulin resistance," Journal of Clinical Investigation, vol. 95, no. 5, pp. 2409-2415, 1995.

[72] J. P. Warne, "Tumour necrosis factor alpha: a key regulator of adipose tissue mass," Journal of Endocrinology, vol. 177, no. 3, pp. 351-355, 2003.

[73] H. Ruan, N. Hacohen, T. R. Golub, L. Van Parijs, and H. F. Lodish, "Tumor necrosis factor-alpha suppresses adipocytespecific genes and activates expression of preadipocyte genes in 3T3-L1 adipocytes: nuclear factor-kappaB activation by TNF-alpha is obligatory," Diabetes, vol. 51, no. 5, pp. 13191336, 2002.

[74] V. Mohamed-Ali, L. Flower, J. Sethi, et al., "Beta-adrenergic regulation of IL-6 release from adipose tissue: in vivo and in vitro studies," Journal of Clinical Endocrinology and Metabolism, vol. 86, pp. 5864-5869, 2001.
[75] P. A. Kern, S. Ranganathan, C. Li, L. Wood, and G. Ranganathan, "Adipose tissue tumor necrosis factor and interleukin-6 expression in human obesity and insulin resistance," American Journal of Physiology, vol. 280, no. 5, pp. E745-E751, 2001.

[76] A. S. Greenberg, R. P. Nordan, J. McIntosh, J. C. Calvo, R. O. Scow, and D. Jablons, "Interleukin 6 reduces lipoprotein lipase activity in adipose tissue of mice in vivo and in 3T3L1 adipocytes: a possible role for interleukin 6 in cancer cachexia," Cancer Research, vol. 52, no. 15, pp. 4113-4116, 1992.

[77] G. Strassmann, M. Fong, J. S. Kenney, and C. O. Jacob, "Evidence for the involvement of interleukin 6 in experimental cancer cachexia," Journal of Clinical Investigation, vol. 89, no. 5, pp. 1681-1684, 1992.

[78] J. M. Bruun, S. B. Pedersen, K. Kristensen, and B. Richelsen, "Opposite regulation of interleukin-8 and tumor necrosis factor-alpha by weight loss," Obesity Research, vol. 10, no. 6, pp. 499-506, 2002.

[79] M. S. Zumbach, M. W. J. Boehme, P. Wahl, W. Stremmel, R. Ziegler, and P. P. Nawroth, "Tumor necrosis factor increases serum leptin levels in humans," Journal of Clinical Endocrinology and Metabolism, vol. 82, no. 12, pp. 40804082, 1997.

[80] S. Loffreda, S. Q. Yang, H. Z. Lin, et al., "Leptin regulates proinflammatory immune responses," FASEB Journal, vol. 12, no. 1, pp. 57-65, 1998.

[81] M. Haluzik, M. Matoulek, S Svacina, et al., "The influence of short-term fasting on serum leptin levels, and selected hormonal and metabolic parameters in morbidly obese and lean females," Endocrine Research, vol. 27, no. 1-2, pp. 251260, 2001.

[82] D. D. Sin and S. F. P. Man, "Impaired lung function and serum leptin in men and women with normal body weight: a population based study," Thorax, vol. 58, no. 8, pp. 695-698, 2003.

[83] E. C. Creutzberg, A. M. Schols, C. A. Weling-Scheepers, W. A. Buurman, and E. F. M. Wouters, "Characterization of nonresponse to high caloric oral nutritional therapy $\mathrm{m}$ depleted patients with chronic obstructive pulmonary disease," American Journal of Respiratory and Critical Care Medicine, vol. 161, no. 3, pp. 745-752, 2000.

[84] T. Yamauchi, J. Kamon, H. Waki, et al., "The fat-derived hormone adiponectin reverses insulin resistance associated with both lipoatrophy and obesity," Nature Medicine, vol. 7, no. 8, pp. 941-946, 2001.

[85] J. M. Bruun, A. S. Lihn, C. Verdich, et al., "Regulation of adiponectin by adipose tissue-derived cytokines: in vivo and in vitro investigations in humans," American Journal of Physiology, vol. 285, no. 3, pp. E527-E533, 2003.

[86] G. Krommidas, K. Kostikas, G. Papatheodorou, et al., "Plasma lepin and adiponectin in COPD exacerbations: associations with inflammatorz biomarkers," Respiratory Medicine, vol. 104, no. 1, pp. 40-41, 2010.

[87] T. Skurk, C. Alberti-Huber, C. Herder, and H. Hauner, "Relationship between adipocyte size and adipokine expression and secretion," Journal of Clinical Endocrinology and Metabolism, vol. 92, no. 3, pp. 1023-1033, 2007.

[88] J.-P. Bastard, C. Jardel, E. Bruckert, et al., "Elevated levels of interleukin 6 are reduced in serum and subcutaneous adipose tissue of obese women after weight loss," Journal of Clinical Endocrinology and Metabolism, vol. 85, no. 9, pp. 3338-3342, 2000. 
[89] M. Maachi, L. Pieroni, E. Bruckert, et al., "Systemic lowgrade inflammation is related to both circulating and adipose tissue TNF $\alpha$, leptin and IL-6 levels in obese women," International Journal of Obesity, vol. 28, no. 8, pp. 993-997, 2004.

[90] M.-C. Alessi, D. Bastelica, P. Morange, et al., "Plasminogen activator inhibitor 1, transforming growth factor-b1, and BMI are closely associated in human adipose tissue during morbid obesity," Diabetes, vol. 49, no. 8, pp. 1374-1380, 2000.

[91] L. K. M. Summers, J. S. Samra, S. M. Humphreys, R. J. Morris, and K. N. Frayn, "Subcutaneous abdominal adipose tissue blood now: variation within and between subjects and relationship to obesity," Clinical Science, vol. 91, no. 6, pp. 679-683, 1996.

[92] B. Chen, K. S. L. Lam, Y. Wang, et al., "Hypoxia dysregulates the production of adiponectin and plasminogen activator inhibitor-1 independent of reactive oxygen species in adipocytes," Biochemical and Biophysical Research Communications, vol. 341, no. 2, pp. 549-556, 2006.

[93] N. Hosogai, A. Fukuhara, K. Oshima, et al., "Adipose tissue hypoxia in obesity and its impact on adipocytokine dysregulation,” Diabetes, vol. 56, no. 4, pp. 901-911, 2007.

[94] R. H. Wenger, "Cellular adaptation to hypoxia: O2-sensing protein hydroxylases, hypoxia-inducible transcription factors, and O2-regulated gene expression," FASEB Journal, vol. 16, no. 10, pp. 1151-1162, 2002.

[95] I. F. Charo and M. B. Taubman, "Chemokines in the pathogenesis of vascular disease," Circulation Research, vol. 95, no. 9, pp. 858-866, 2004.

[96] S. E. Shoelson, J. Lee, and M. Yuan, "Inflammation and the $\mathrm{IKK} \beta / \mathrm{I} \kappa \mathrm{B} / \mathrm{NF}-\kappa \mathrm{B}$ axis in obesity- and diet-induced insulin resistance," International Journal of Obesity, vol. 27, supplement 3, pp. S49-S52, 2003.

[97] G. L. Semenza, "HIF-1 and mechanisms of hypoxia sensing," Current Opinion in Cell Biology, vol. 13, no. 2, pp. 167-171, 2001.

[98] G. L. Semenza, “Targeting HIF-1 for cancer therapy," Nature Reviews Cancer, vol. 3, no. 10, pp. 721-732, 2003.

[99] S. Rocha, "Gene regulation under low oxygen: holding your breath for transcription," Trends in Biochemical Sciences, vol. 32, no. 8, pp. 389-397, 2007.

[100] P. Trayhurn, B. Wang, and I. S. Wood, "Hypoxia and the endocrine and signalling role of white adipose tissue," Archives of Physiology and Biochemistry, vol. 114, no. 4, pp. 267-276, 2008.

[101] N. Takabatake, H. Nakamura, S. Abe, et al., "The relationship between chronic hypoxemia and activation of the tumor necrosis factor-aplha system in patients with chronic obstructive pulmonary disease," American Journal of Respiratory and Critical Care Medicine, vol. 161, no. 4, pp. 1179-1184, 2000.

[102] G. S. Supinski and L. A. Callahan, "Free radical-mediated skeletal muscle dysfunction in inflammatory conditions," Journal of Applied Physiology, vol. 102, no. 5, pp. 2056-2063, 2007.

[103] R. Tkacova, Z. Kluchova, P. Joppa, D. Petrasova, and A. Molcanyiova, "Systemic inflammation and systemic oxidative stress in patients with acute exacerbations of COPD," Respiratory Medicine, vol. 101, no. 8, pp. 1670-1676, 2007.

[104] P. Lévy, M. R. Bonsignore, and J. Eckel, "Sleep, sleepdisordered breathing and metabolic consequences," European Respiratory Journal, vol. 34, no. 1, pp. 243-260, 2009.
[105] A. Barcelo, F. Barbe, E. Llompart, et al., "Effects of obesity on C-reactive protein level and metabolic disturbances in male patients with obstructive sleep apnea," American Journal of Medicine, vol. 117, no. 2, pp. 118-121, 2004.

[106] S. Ryan, C. T. Taylor, and W. T. McNicholas, "Predictors of elevated nuclear factor- $\kappa \mathrm{B}$-dependent genes in obstructive sleep apnea syndrome," American Journal of Respiratory and Critical Care Medicine, vol. 174, no. 7, pp. 824-830, 2006.

[107] Z. Dorkova, D. Petrasova, A. Molcanyiova, M. Popovnakova, and R. Tkacova, "Effects of continuous positive airway pressure on cardiovascular risk profile in patients with severe obstructive sleep apnea and metabolic syndrome," Chest, vol. 134, no. 4, pp. 686-692, 2008.

[108] J. Li, D. N. Grigoryev, S. Q. Ye, et al., "Chronic intermittent hypoxia upregulates genes of lipid biosynthesis in obese mice," Journal of Applied Physiology, vol. 99, no. 5, pp. 1643-1648, 2005.

[109] N. Iiyori, L. C. Alonso, J. Li, et al., "Intermittent hypoxia causes insulin resistance in lean mice independent of autonomic activity," American Journal of Respiratory and Critical Care Medicine, vol. 175, no. 8, pp. 851-857, 2007.

[110] J. Li, V. Savransky, A. Nanayakkara, P. L. Smith, C. P. O’Donnell, and V. Y. Polotsky, "Hyperlipidemia and lipid peroxidation are dependent on the severity of chronic intermittent hypoxia," Journal of Applied Physiology, vol. 102, no. 2, pp. 557-563, 2007.

[111] T. Yokoe, L. C. Alonso, L. C. Romano, et al., "Intermittent hypoxia reverses the diurnal glucose rhythm and causes pancreatic $\beta$-cell replication in mice," Journal of Physiology, vol. 586, no. 3, pp. 899-911, 2008.

[112] A. Bruno, P. Chanez, G. Chiappara, et al., "Does leptin play a cytokine-like role within the airways of COPD patients?" European Respiratory Journal, vol. 26, no. 3, pp. 398-405, 2005.

[113] M. Miller, J. Y. Cho, A. Pham, J. Ramsdell, and D. H. Broide, "Adiponectin and functional adiponectin receptor 1 are expressed by airway epithelial cells in chronic obstructive pulmonary disease," Journal of Immunology, vol. 182, no. 1, pp. 684-691, 2009.

[114] J. H. J. Vernooy, N. E. A. Drummen, R. J. van Suylen, et al., "Enhanced pulmonary leptin expression in patients with severe COPD and asymptomatic smokers," Thorax, vol. 64, no. 1, pp. 26-32, 2009.

[115] N. N. Hansel, L. Gao, N. M. Rafaels, et al., "Leptin receptor polymorphisms and lung function decline in COPD," European Respiratory Journal, vol. 34, no. 1, pp. 103-110, 2009.

[116] S. A. Shore, R. D. Terry, L. Flynt, A. Xu, and C. Hug, "Adiponectin attenuates allergen-induced airway inflammation and hyperresponsiveness in mice," Journal of Allergy and Clinical Immunology, vol. 118, no. 2, pp. 389-395, 2006.

[117] G. L. Sorensen, J. V. B. Hjelmborg, R. Leth-Larsen, et al., "Surfactant protein D of the innate immune defence is inversely associated with human obesity and SP-D deficiency infers increased body weight in mice," Scandinavian Journal of Immunology, vol. 64, no. 6, pp. 633-638, 2006.

[118] G. L. Sørensen, J. V.B. Hjelmborg, K. O. Kyvik, et al., "Genetic and environmental influences of surfactant protein D serum levels," American Journal of Physiology, vol. 290, no. 5, pp. L1010-L1017, 2006. 


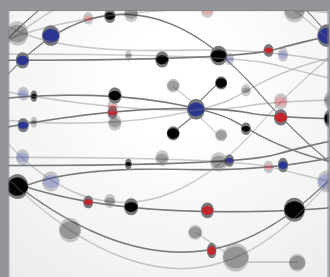

The Scientific World Journal
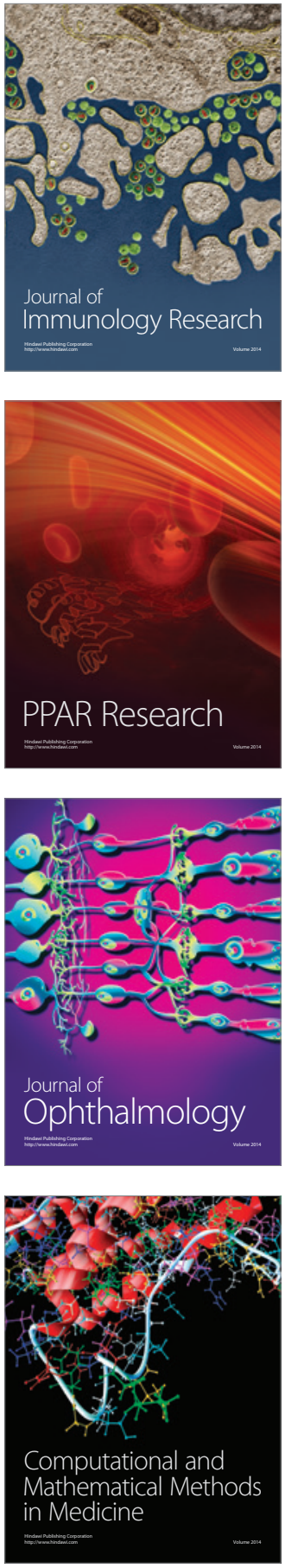

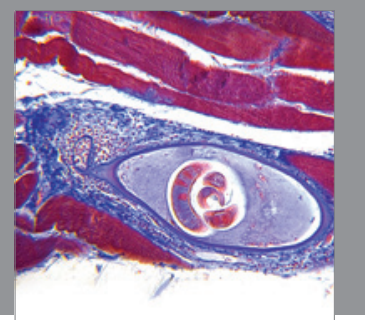

Gastroenterology

Research and Practice
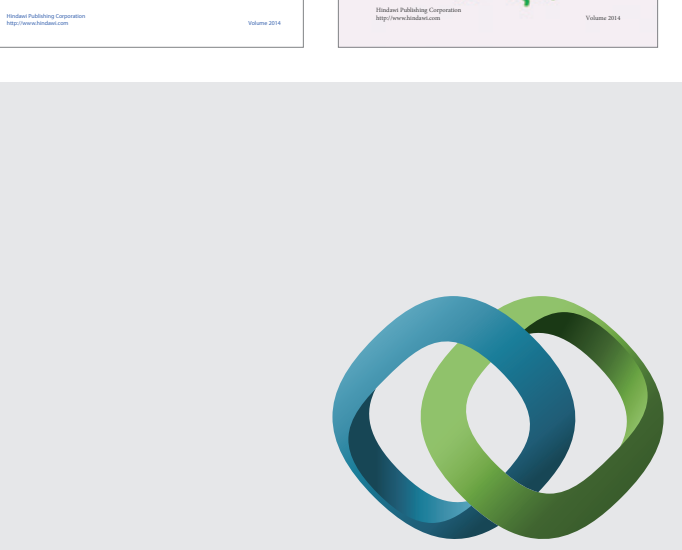

\section{Hindawi}

Submit your manuscripts at

http://www.hindawi.com
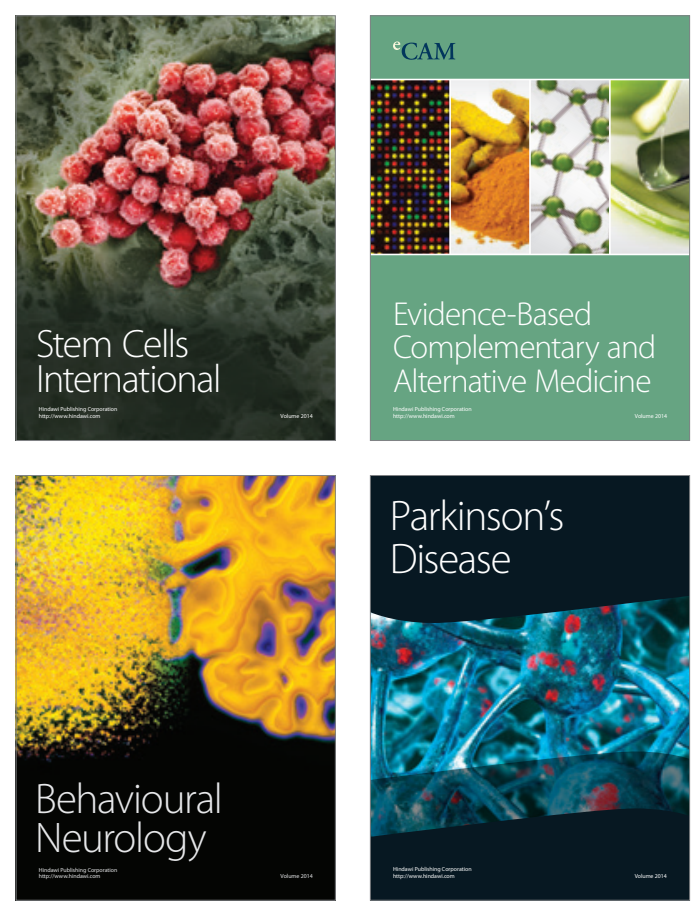

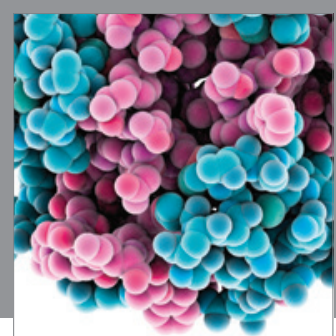

Journal of
Diabetes Research

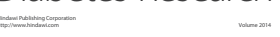

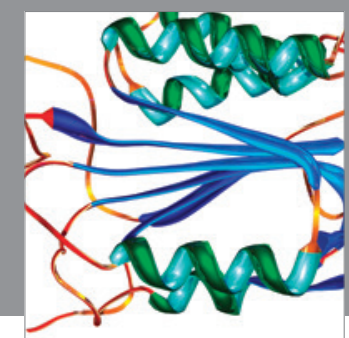

Disease Markers
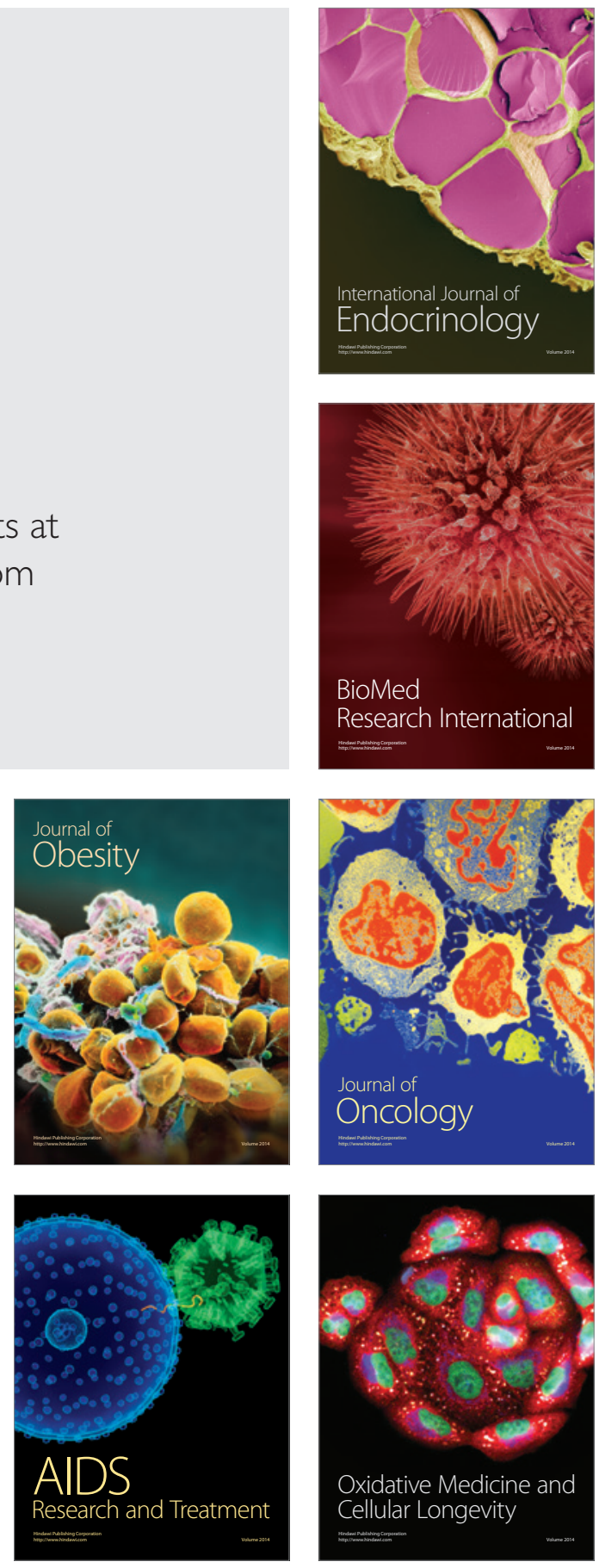